By the end, Sancho Panza's descent into these fantastic delusions is complete. So much so that at his death bed, when Don Quixote regains a measure of lucidity and tries to persuade Sancho to see reason, Sancho Panza is completely insightless and unamenable.

We are not witness to the effect of the separation of Sancho Panza from Don Quixote, as the story ends before it. But apart from that, the description of folie à deux is complete in this wonderfully told tale.

1 de Barros DM, Filho GB. First fictional report of folie à deux. Br J Psychiatry 2011; 198: 30

2 de Cervantes M. Don Quixote (trans JM Cohen). Penguin, 1950.

Vijay Kumar, Consultant Psychiatrist in Old Age Psychiatry, Cheshire and Wirral Partnership NHS Foundation Trust, Jocelyn Solly House, Macclesfield, UK. Email: vijay76@hotmail.co.uk

doi: 10.1192/bjp.198.4.326a

\section{The benefits of an active control arm}

Lesem et al $^{1}$ highlight the importance of rapid and safe treatment of agitation, indicating the delayed onset of action associated with intramuscular injection. They make no reference to the time from oral medication administration to onset of effect. However, the combination of oral atypical antipsychotics, with or without benzodiazepines, is well described. ${ }^{2}$ Small trials have compared the efficacy of oral atypical antipsychotics with that of intramuscular typicals and produced mean changes in rating scale scores similar to those in Lesem et aPs paper, on similar timescales. ${ }^{3}$

When alternative treatments exist, placebo-controlled trials are appropriate if the target condition is characterised by a high placebo-response rate or a high relapse, remission or spontaneous resolution rate, or if existing therapies are partially effective or have high side-effect rates. ${ }^{4}$ Inclusion of an active control arm to the trial would have added to the number of patients required in each arm, but would have provided valuable information on the tolerability and efficacy of the inhaled or oral medication.

1 Lesem MD, Tran-Johnson TK, Riesenberg RA, Feifel D, Allen MH, Fishman R, et al. Rapid acute treatment of agitation in individuals with schizophrenia: multicentre, randomised, placebo-controlled study of inhaled loxapine. $\mathrm{Br} J$ Psychiatry 2011; 198: 51-8.

2 Yildiz A, Sachs G, Turgay A. Pharmacological management of agitation in emergency settings. Emerg Med J 2003; 20: 339-46.

3 Lim HK, Kim JJ, Pae CU, Lee CU, Lee C, Paik IH. Comparison of risperidone orodispersible tablet and intramuscular haloperidol in the treatment of acute psychotic agitation: a randomized open, prospective study. Neuropsychobiology 2010; 62: 81-6.

4 Emanuel EJ, Miller FG. The ethics of placebo controlled trials - a middle ground. N Engl J Med 2001; 345: 915-9.

Andy R. Shepherd, CT1 Trainee, Greater Manchester West Mental Health Trust. Email: andy.shepherd81@gmail.com

doi: 10.1192/bjp.198.4.327

\title{
Corrections
}

Mental disorders and termination of education in high-income and low- and middle-income countries: epidemiological study. $B J P, 194,411-417$. The following funding source was omitted from the start of the list on p. 416: US National Institute of Mental Health - Mental Health Burden Study (contract number HHSN271200700030C).
The man behind Philippe Pinel: Jean-Baptiste Pussin (17461811). BJP, 198, 241. The DOI for this item is: 10.1192/ bjp.198.3.241a. The online version has been corrected in deviation from print and in accordance with this correction. 